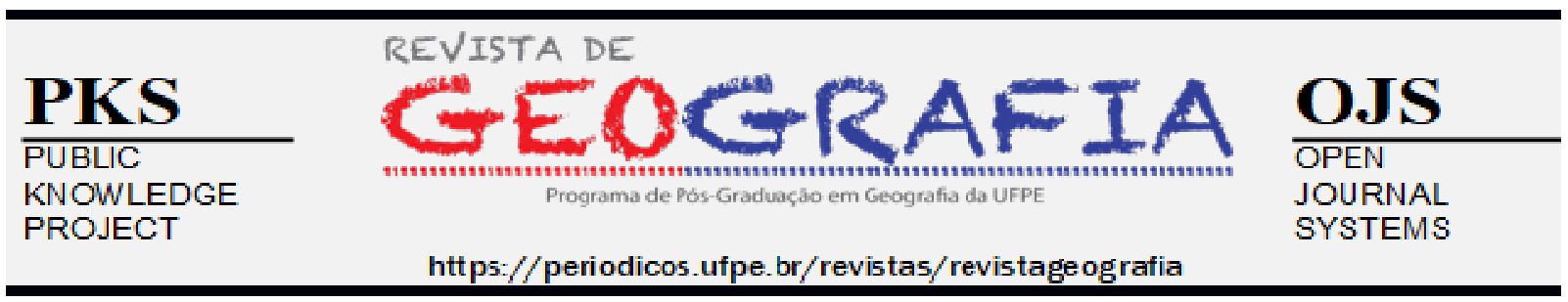

\title{
A CONSTRUÇÃO DO ESTADO DA ARTE DAS PESQUISAS SOBRE PRÁTICAS DE ENSINO EM GEOGRAFIA (2013 - 2018)
}

\author{
João Antonio Blois Aita1, Victor Hugo Nedel Oliveira²
}

1 Licenciando em Geografia pela Universidade Federal do Rio Grande do Sul, E-mail: joao.antonio.aita@gmail.com, ORCID: https://orcid.org/0000-0002-9484-7872

2 Doutor em Educação, Professor e pesquisador na Universidade Federal do Rio Grande do Sul, E-mail: victor.juventudes@gmail.com, ORCID: https://orcid.org/0000-0001-5624-8476

Artigo recebido em 06/01/2021 e aceito em 07/05/2021

\begin{abstract}
RESUMO
A temática do ensino de Geografia tem ganhado notoriedade no campo científico nos últimos anos na medida em que se observa um crescimento na quantidade de trabalhos desenvolvidos. O principal objetivo do presente texto é apresentar a construção inicial do estado do conhecimento das pesquisas sobre ensino de Geografia, no âmbito da pós-graduação brasileira. Para tanto, foi desenvolvida investigação de levantamento bibliográfico, de forma a compor a reunião, a seleção e desenvolver a análise das pesquisas produzidas entre 2013 e 2018. Dentre os principais resultados evidenciados, verificou-se que a maior parte dos trabalhos é de mestrado e que a maioria não recebeu financiamento por meio de bolsas e, quando fomentados, a Capes e o CNPq foram as principais agências. As produções concentram-se majoritariamente nas regiões Sul e Sudeste do país. As instituições UFRGS, UFG e USP são as universidades que mais apresentaram pesquisas do gênero. A maior parte dos Programas de Pós-Graduação, na análise da Capes, foram classificados com nota 5. Nesse sentido, é possível considerar que há urgência tanto em relação à concessão quanto ao aumento do número de bolsas e que ainda persiste a concentração da produção de pós-graduação na região concentrada. Muitos esforços ainda devem ser tomados para que a realidade da pesquisa no ensino de Geografia adquira novos horizontes.
\end{abstract}

Palavras-chave: práticas de ensino; ensino de Geografia; estado da arte.

\section{THE CONSTRUCTION OF THE STATE OF RESEARCH ART ON TEACHING PRACTICES IN GEOGRAPHY (2013 - 2018)}

\begin{abstract}
The subject of Geography teaching has gained notoriety in the scientific field in recent years as there is an increase in the amount of work developed. The main objective of this text is to present the initial construction of the state of knowledge of research on teaching Geography, within the scope of Brazilian graduate studies. To this end, a bibliographic survey investigation was carried out, in order to compose the meeting, selection and develop the analysis of the researches produced between 2013
\end{abstract}


and 2018. Among the main evidenced results, it was found that most of the works are master's and that the majority did not receive funding through grants and, when promoted, Capes and CNPq were the main agencies. Production is mainly concentrated in the South and Southeast regions of the country. UFRGS, UFG and USP are the universities that most presented research of this kind. Most of the Graduate Programs, in Capes 'analysis, were classified with a score of 5. In this sense, it is possible to consider that there is urgency both in terms of the granting and the increase in the number of scholarships and that the concentration of production still persists. graduate programs in the concentrated region. Many efforts still need to be made so that the reality of research in the teaching of Geography acquires new horizons.

Keywords: teaching practices; Geography teaching; state of art.

\section{LA CONSTRUCCIÓN DEL ESTADO DE LA INVESTIGACIÓN SOBRE PRÁCTICAS DIDÁCTICAS EN GEOGRAFÍA (2013 - 2018)}

\section{RESUMEN}

El tema de la enseñanza de la Geografía ha ganado notoriedad en el campo científico en los últimos años al haber un aumento en la cantidad de trabajo desarrollado. El objetivo principal de este texto es presentar la construcción inicial del estado del conocimiento de la investigación sobre la enseñanza de la Geografía, en el ámbito de los estudios de posgrado brasileños. Para ello, se realizó una investigación de relevamiento bibliográfico, con el fin de componer el encuentro, selección y desarrollar el análisis de las investigaciones producidas entre 2013 y 2018. Entre los principales resultados evidenciados, se encontró que la mayoría de los trabajos son de maestría y que la mayoría no recibió financiamiento a través de donaciones y, cuando se promovió, Capes y CNPq fueron las principales agencias. La producción se concentra principalmente en las regiones Sur y Sudeste del país. UFRGS, UFG y USP son las universidades que más presentaron investigaciones de este tipo. La mayoría de los Programas de Posgrado, en el análisis de Capes, fueron clasificados con un puntaje de 5. En este sentido, se puede considerar que existe urgencia tanto en el otorgamiento como en el aumento del número de becas y que la concentración de la producción aún persiste. programas de posgrado en la región concentrada. Aún quedan muchos esfuerzos por hacer para que la realidad de la investigación en la enseñanza de la Geografía adquiera nuevos horizontes.

Palabras clave: prácticas docentes; enseñanza de Geografía. estado del arte.

\section{INTRODUÇÃO}

$\mathrm{O}$ aumento no número de pesquisas que abordam a temática do ensino em geografia representa grande destaque para a ciência geográfica e para a formação de professores do campo de Geografia. Através dessas investigações, pode-se avançar rumo ao desenvolvimento de seguir aprendendo sobre as formas de ensinar e se aprender em Geografia. O aprender e ensinar geografia, portanto, estão relacionados à construção de condições suficientes para que os alunos conheçam sua posição no mundo e também tomar posição no mundo, posicionandose política e criticamente. As pesquisas sobre práticas de ensino em Geografia são aquelas que 
irão fomentar a formação de estudantes conscientes uma vez que são elas que desenvolvem, debatem e aprimoram as técnicas de ensino-aprendizagem.

As discussões sobre práticas de ensino em Geografia são, no geral, protagonizadas pela temática das Metodologias Ativas. Partindo do pressuposto de que a construção de conhecimento é interativa, essa opção metodológica tem como objetivo o protagonismo do aluno em seu processo de construção do conhecimento. Há uma outra concepção que considera as metodologias ativas como aquelas que não se utilizam de métodos passivos. Sendo assim, ler um texto ou observar um instrutor fazendo algo é considerado uma aprendizagem passiva (MORAES; CASTELLAR, 2018). Portanto, as Metodologias Ativas concentram esforços na participação do aluno na problematização e resolução de problemas, uma vez que cada aluno tem sua maneira de aprender e cabe a ele construir seus próprios modelos mentais construção do conhecimento (RABELO; BORBA, 2019).

É fundamental que essa metodologia não seja utilizada apenas como um modo de tornar aulas entediantes em aulas atrativas ao aluno. O objetivo é fornecer ao aluno "condições para que se construa o sentido de um determinado conceito ou conteúdo que o professor pretende desenvolver" (MORAES et al, 2014, p.250) com o intuito de oportunizar a formação crítica e reflexiva do aluno. Dentro deste aspecto, Moran $(2018$, p. 2) considera que o professor está se tornando cada vez mais uma espécie de orientador de caminhos coletivos e individuais. Nesse sentido, as pesquisas em práticas se consolidam também como parte das referências teóricas dos docentes ao longo de sua trajetória em vista desta mudança de atuação.

No contexto das políticas educacionais e curriculares, a Base Nacional Comum Curricular (BNCC) apareceu como um instrumento de "sistematização dos conhecimentos, seleção e ordenação de conteúdos" (GUIMARÃES, 2018, p. 1037). Guimarães também cita em seu trabalho o contexto conturbado da elaboração da BNCC e que fez com que esses embates se refletissem em seu texto. Sendo assim, segundo o autor, o documento pode limitar a autonomia do docente de modo a ditar o que deve ser trabalhado, atribuição de propriedade do docente. E é neste sentido que a mesma nunca será efetivamente implantada (GUIMARÃES, 2018, p. 1053).

Apesar destas inquietações, referentes a estes aspectos delicados referidos acima, a BNCC presa, de algum modo, pelo protagonismo do aluno referente a seu processo de ensino 
aprendizagem. Sendo assim, a atuação do professor fica tensionada entre a limitação dos conteúdos da base e sua nevrálgica autonomia referente aos processos didáticos em sala de aula. Sabendo que os alunos possuem seus próprios modos de construção de conhecimento e que os mesmos possuem diferentes modos de relação com o espaço geográfico podemos considerar que, mais do que nunca, a atribuição do professor é extremamente complexa. Sendo assim, reforça-se a importância dos estudos sobre práticas de ensino em Geografia de modo a respaldar e dar referência para a atuação dos profissionais docentes contrapondo não só a educação convencional, mas freando as tentativas de apropriação desse processo pelos interesses do mercado e neoliberalismo visando-se assim a formação de cidadãos plenos e críticos.

As investigações que se utilizam do estado do conhecimento (MOROSINI; FERNANDES, 2014) e que objetivam elaborar o estado da arte dessas pesquisas também auxiliam os pesquisadores a compreender em que posição se encontra determinado campo da ciência. Mais especificamente, auxiliam a conhecer tanto o que está sendo produzido e discutido quanto aquilo que não está ganhando destaque analítico. São estudos que fornecem condições necessárias para se averiguar o estado que se encontra a ciência, suas peculiaridades e, ainda, contribuem para o ineditismo das produções. De caráter inventariante e descritivo (FERREIRA, 2002) o estado do conhecimento ampara o pesquisador ao dar informações sobre o tema que busca investigar. Através desse caráter, essa ciência também permite refletir a respeito do momento político e econômico do país e quais foram as implicações levadas pelos temas investigados nas pesquisas.

Permeados por essas leituras, este trabalho se justifica pelo anseio de pensar quantitativa e qualitativamente a respeito do que se produz, em nível de pós-graduação, sobre ensino de Geografia. Ao mesmo tempo contribuir para o desenvolvimento das futuras pesquisas ao situar os geógrafos garantindo a qualidade, diversidade e o ineditismo dos trabalhos.

Alguns autores e autoras já se debruçaram sobre o tema da construção de um estado do conhecimento no campo do ensino de Geografia. Fonseca (2019) buscou, em seu trabalho, construir o estado da arte das pesquisas em ensino de geografia publicadas em periódicos nacionais. Rabelo e Borba (2019) também visaram a construção de um estado da arte, porém na perspectiva das pesquisas sobre metodologias ativas no ensino de geografia explorando as 
contribuições para uma ressignificação do ensino. Côrrea (2019), por sua vez, pretendeu construir o estado da arte do ensino de geografia, investigando a respeito de como as novas tecnologias contribuem para o ensino. Destacam-se ainda outros trabalhos como o de Gomes e Pazio (2015) que aborda o estado da arte das pesquisas em geotecnologias no ensino de geografia e o de Fonseca et al (2014) no qual se esforçaram em construir um estado da arte das dissertações de mestrados que versam a respeito do ensino de Geografia.

O presente artigo diferencia-se dessas produções por estar relacionado especificamente a construção de um estado da arte daquelas teses e dissertações que versam a respeito das práticas de ensino em Geografia ao passo que outras investigações abordam a temática de forma mais geral ou, ainda, em outras óticas e contextos mais específicos. Desta forma, visa-se contribuir para o avanço desta temática através do recolhimento e análise de informações a respeito das teses e dissertações encontradas na Biblioteca Digital de Teses e Dissertações (BDTD) entre os anos de 2013 e 2018.

\section{METODOLOGIA}

Optou-se metodologicamente pela estratégia de revisão bibliográfica (GIL, 2007) utilizando-se da construção de estado do conhecimento, que possui base metodológica amparada em Morosini e Fernandes (2014, p. 155) sendo definido como a "identificação, registro, categorização que levem à reflexão e síntese sobre a produção científica de uma determinada área, em um determinado espaço de tempo, congregando periódicos, teses, dissertações e livros sobre uma temática específica”.

Desse modo, o primeiro movimento metodológico para a construção desse trabalho foi a identificação e o registro dos trabalhos sobre práticas de ensino de Geografia disponíveis na Biblioteca Digital Brasileira de Teses e Dissertações - BDTD do Instituto Brasileiro de Informação em Ciência e Tecnologia - IBICT. Após isso, foi efetuada a extração de informações que seriam relevantes para análise e através dessas informações foi realizada categorizações adequadas a cada tipo de informação.

O Instituto Brasileiro de informação em Ciência e Tecnologia é uma instituição datada do ano de 1954 que teve sua criação influenciada pela UNESCO com o intuito de incentivar e criar um tipo de serviço que reunisse, efetuasse a documentação e a organização da bibliografia produzida no país de forma a maximizar o aproveitamento das bibliografias e 
documentos reunidos pela comunidade científica. Um dos recursos de posse do instituto é a Biblioteca Digital Brasileira de Teses e Dissertações (BDTD) que se trata de um dos maiores bancos de dados de pesquisas em nível de teses e dissertações. Nessa perspectiva, o banco de dados se constitui como uma excelente base de dados para esta pesquisa.

Selecionou-se o recorte temporal de 2013 a 2018 em função de que foi considerado que cinco anos compreende um período em que as análises fossem exequíveis, a partir da consolidação das publicações já tendo sido depositadas no referido banco de dados e, com isso, que refletissem a realidade. Para o refino da busca pelos artigos, procurou-se por artigos que tratassem do tema de práticas de ensino em geografia especificamente, através de descritores como palavras-chave de presença simultânea e/ou individuais como "práticas de ensino", "ensino de Geografia”, "Geografia”, “escola”. Após, prosseguiu-se para a etapa de conclusão da construção do corpus da pesquisa através da leitura dos resumos e consequente seleção dos trabalhos.

Após a triagem inicial, 123 trabalhos foram selecionados, dos quais foi extraída uma série de dados de cada trabalho para análise da investigação. Verificaram-se os tipos de trabalho (tese ou dissertação), com o fim de verificar em qual nível da pós-graduação encontra-se a maioria das pesquisas; seus respectivos anos de publicação, objetivando verificar o comportamento da quantidade de produções por ano; as universidades de cada trabalho e a região do país em que se encontram, a fim de conhecer quais instituições mais se fazem presentes na discussão do tema em nível de pós-graduação assim como em quais partes do território brasileiro o assunto é mais abordado. Também foram verificados quais trabalhos foram fomentados por bolsas e quais agências auxiliaram os pesquisadores, deste modo podese concluir qual a agência é mais presente nas pesquisas brasileiras sobre práticas de ensino de Geografia e qual a quantidade de trabalhos que foram beneficiados pelas agências de fomento. E, por último, observaram-se quais eram os conceitos dos programas de pós-graduação com o intuito de verificar tanto a qualidade dos PPGs quanto quais PPGs dão mais atenção ao tema. Além desses enfoques principais, foi possível tecer outras análises e conclusões que permitiram uma maior profundidade na abordagem do assunto em tela.

Eticamente, a presente pesquisa está isenta de submissão ao Comitê de Ética, em uma leitura da Resolução No 510/2016 (BRASIL, 2016a) do Conselho Nacional de Saúde (CNS), a qual versa em seu Art. $1^{\circ}$ que as pesquisas de revisão de literatura não necessitam de 
tal demanda, por tratar-se de investigações realizadas a partir de material de domínio público já publicado.

\section{RESULTADOS}

No gráfico 1, é possível observar a distribuição dos tipos de trabalhos selecionados para análise, entre dissertações e teses.

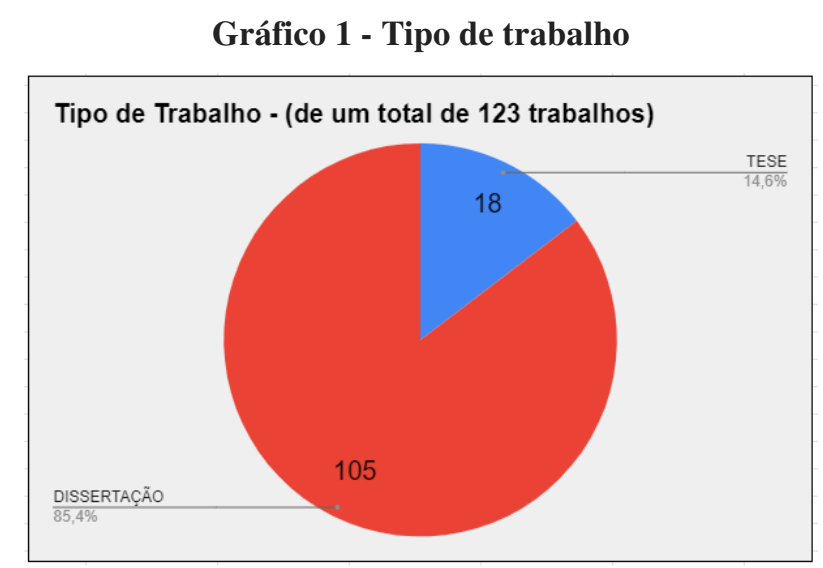

Fonte: banco de dados da pesquisa (2020)

Percebe-se, a partir da análise do gráfico 1, que as dissertações somaram 85,4\% ( $\mathrm{n}=$ 105) dos trabalhos selecionados que compuseram o corpus da investigação, e que, consequentemente, as teses somaram $14,6 \%$ dos trabalhos $(n=18)$. É possível inferir, dessa forma, que o número expressivo de dissertações apresentadas, em detrimento das teses, aponta para o fato de que o tema das práticas de ensino de Geografia ainda encontra-se, majoritariamente, na esfera do mestrado.

Ao analisar o banco de dados da Biblioteca Digital Brasileira de Teses e Dissertações (BDTD) é possível observar e tecer comparações do número de teses e dissertações encontradas nos trabalhos selecionados com os números gerais dos trabalhos de mestrado e doutorado no Brasil. Desse modo, aponta-se em que pontos as pesquisas em práticas de ensino em Geografia se diferenciam do aspecto geral da pesquisa.

No período de 2013 a 2018, o referido banco de dados indica que foram realizadas e registradas no repositório 200.184 dissertações e 76.499 teses. Em uma análise proporcional há, aproximadamente 2,61 trabalhos de mestrado para cada trabalho de doutorado. As pesquisas selecionadas no presente trabalho, apontam que existem 5,83 trabalhos de mestrado em práticas de ensino em Geografia para cada trabalho em nível de doutorado. Sendo assim, é possível perceber que existe uma desproporcionalidade em relação aos números 
comparativos, já que as pesquisas em práticas de ensino em Geografia apresentam um número proporcionalmente superior de dissertações em relação às teses. Dessa forma, é possível perceber que os trabalhos concentram-se no nível de mestrado e que, na maioria das vezes, os esforços das dissertações não se convertem em uma continuidade em direção ao doutorado.

É possível observar, no gráfico 2, a quantidade de trabalhos a cada ano adotado no recorte temporal da pesquisa $(2013-2018)$.

Gráfico 2 - Número de trabalhos por ano

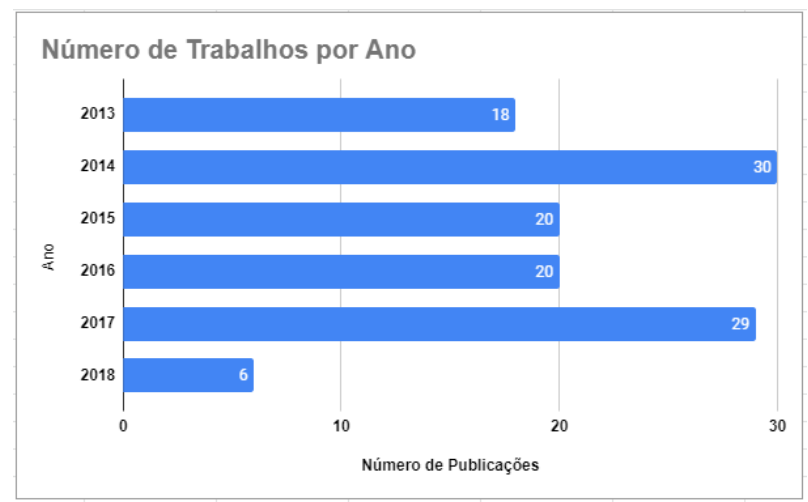

Fonte: banco de dados da pesquisa (2020)

Visualiza-se no gráfico que a produção de trabalhos (mestrado e doutorado) não se comportou de maneira constante ao longo do recorte temporal da pesquisa, havendo significativas diferenças no intervalo de 2013 - 2014 e 2016 - 2017. Uma vez que esses tipos de trabalhos levam de 2 a 4 anos para serem concluídos é normal que os números não se apresentem de forma constante, mas constitui-se importante ressaltar o momento de turbulência e incerteza gerado pela Emenda Constitucional n. ${ }^{\circ} 95$ (BRASIL, 2016b), conhecida como Emenda do Teto dos Gastos e os impactos que a mesma poderá ter no fomento às pesquisas e que poderá refletir no número de produções científicas, na medida em que os investimentos em educação permanecem congelados o que vem gerando a diminuição constante do fomento da pesquisa e da ciência nacional.

O gráfico 4 evidencia a distribuição dos tipos de trabalhos ao longo do espaço temporal desta pesquisa. 
Gráfico 4 - Tipos de trabalho por ano



Fonte: banco de dados da pesquisa (2020)

Observa-se que em todos os anos há uma diferença entre o número de dissertações e teses em que as dissertações estão sempre em maior quantidade em relação às teses. Números que são observados de forma semelhante em Silva (2017) ao realizar um estudo sintetizando um breve histórico da produção geográfica no Brasil até 2011. O ano de 2017 se deu como um ano atípico para as produções em prática de ensino em Geografia uma vez que, apesar de constar 25 dissertações, observa-se a ocorrência de apenas uma tese.

É possível verificar no gráfico, ainda, a produção científica no nível de mestrado profissional no ano de 2017 com um número maior de trabalhos em relação ao Doutorado. Institucionalizado desde 1995, o Mestrado Profissional (MP) ainda continua a ser um assunto de amplo debate da comunidade acadêmica, em especial no campo das ciências humanas (FISCHER, 2005) dados os questionamentos sobre sua estrutura constituir-se como algo da esfera acadêmica ou não. Em seus princípios, o MP visa ser um curso mais aplicado a formar um profissional pronto para a prática da profissão, enquanto o Mestrado Acadêmico visa a formação de novos pesquisadores. A fonte da polêmica em torno do caráter acadêmico está na abertura do corpo docente não somente a doutores, mas também a mestres e profissionais da área. Deste modo, abre-se o questionamento: por que há tão pouca produção de pesquisas em práticas de ensino em Geografia no Mestrado Profissional? É um tensionamento que a presente pesquisa não comporta discussão, entretanto, abre-se o espaço para o debate no campo do ensino de Geografia.

No gráfico 4 é possível observar a distribuição dos trabalhos selecionados em suas respectivas universidades de origem. 


\section{Gráfico 4 - Quantidade de trabalhos por universidade}

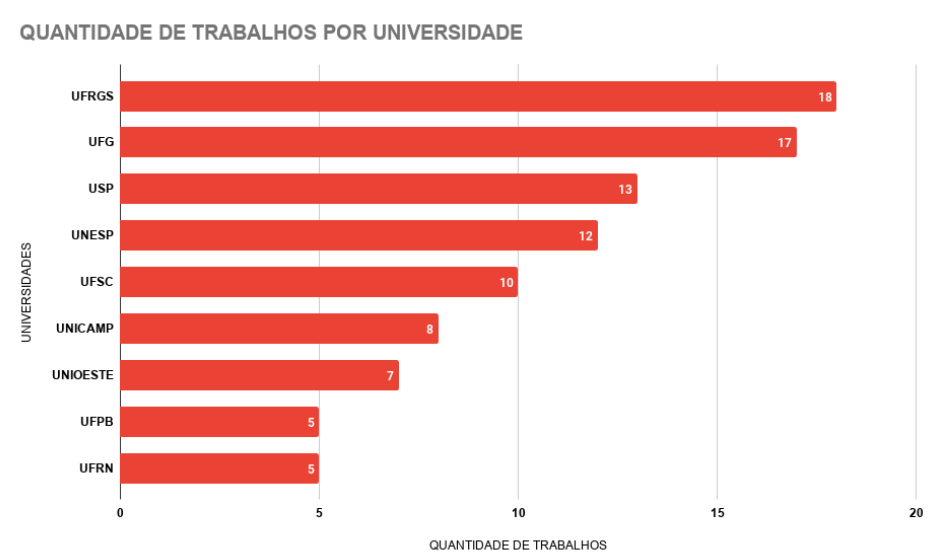

Fonte: banco de dados da pesquisa (2020).

Inicialmente, se faz preciso reconhecer a relevância das Universidades das regiões Sul e Sudeste do Brasil para a produção científica relacionada ao tema desta investigação, relevância que se estende igualmente aos demais campos do saber. São essas as regiões com maior desenvolvimento econômico e social, de acordo com o acumulado de informações apresentadas pelo IBGE. Nesse ponto, retoma-se o conceito de Região Concentrada que Santos (1986) sugere em sua proposta de divisão regional do Brasil e que leva em consideração o "meio técnico-científico-informacional". Ou seja, as universidades que se destacam pela produção no presente trabalho encontram-se na Região Concentrada em que "desde o primeiro momento da mecanização do território, ocorre uma adaptação progressiva e eficiente aos interesses do capital hegemônico" (ELIAS, 2003).

Em um contexto geral, a partir da década de 70, começa o tensionamento da agenda das pesquisas científicas entre a "pesquisa desinteressada" e "interessada", respectivamente, pesquisa básica e pesquisa aplicada (SILVA, 2012). O maior peso foi dado para a pesquisa aplicada, referente ao conhecimento científico, tecnológico e inovador de interesse da esfera privada. Este fato potencializa, de maneira geral, o investimento nestas universidades e fez com que as mesmas despontassem ainda mais em relação a produção acadêmica, uma vez que essas universidades estão localizadas nas duas regiões mais avançadas economicamente do país. Deste modo, pelo fato de suas regiões possuírem maior desenvolvimento econômico e, consequentemente, maior presença de entes privados no mercado, houve maior investimento em pesquisas científicas e consequentemente maior produção acadêmica. Esta maior produção 
acadêmica é retroalimentada pela destinação de verbas que faz com que as universidades destas regiões acabem por produzir mais e recebam mais verbas. Sendo assim, o fenômeno defendido por Milton Santos pode explicar a concentração dos trabalhos nas universidades da Região Concentrada que englobam a Região Sul e Sudeste, as regiões mais desenvolvidas economicamente do país.

Por outro lado, em segundo lugar encontra-se a Universidade Federal de Goiás (UFG), no Centro-Oeste, com dezessete trabalhos em um total de 123. Esta Universidade é a única que quebra a hegemonia Sul-Sudeste. Deste modo, observa-se grande concentração de trabalhos nessa região sobre o tema em apenas uma universidade (UFG) uma vez que é responsável por dezessete dos vinte e dois trabalhos selecionados. A Universidade Federal do Rio Grande do Sul (UFRGS), instituição que mais teve trabalhos selecionados na pesquisa, e a Universidade Estadual de Campinas (UNICAMP) são as que possuem os maiores conceitos na avaliação Capes dos Programas de Pós-Graduação. Ainda nessa perspectiva, essas duas universidades são as únicas do escopo de pesquisa que possuem o PPG em Geografia com conceito 6, o que confere excelência acadêmica.

Destaca-se, também, o quantitativo de instituições públicas para as pesquisas em práticas de ensino em Geografia. De um total de 25 universidades, apenas $8 \%(\mathrm{n}=2)$, a Pontifícia Universidade Católica do Rio Grande do Sul (PUCRS) e a Pontifícia Universidade Católica de São Paulo (PUCSP), são instituições privadas. Cerca de 60\% (n = 15) são instituições federais e $28 \%(\mathrm{n}=7)$ são estaduais. O Governo do Estado de São Paulo se destaca por ser o responsável por três das sete instituições estaduais observadas no levantamento.

A importância da universidade pública, em especial as instituições federais, se mostrou extremamente relevante diante dos números enfatizados no gráfico quatro. Permeados pela influência da globalização e da financeirização (AALBERS, 2015), a sociedade tende a julgar a universidade pública como um investimento caro e com baixo retorno para a sociedade. A disseminação de uma globalização associada a um significado equivalente ao desenvolvimento foi um dos instrumentos criados pelos países desenvolvidos para (re)inserir os países ditos subdesenvolvidos na lógica do capital financeiro. $\mathrm{O}$ neoliberalismo também fez com que "a ideia de universidade e do conhecimento como um 
bem público fosse desalojada pelos aspectos econômicos da educação e da universidade como negócio" (LENCIONI, 2013, p. 7).

Neste sentido, observa-se uma "adequação mecânica e direta do sistema educacional aos padrões organizacionais impostos ao mundo do trabalho" (KAWASAKI, 1997, p. 240), uma vez que a universidade pública foi vista como uma forma de cada vez mais qualificar os profissionais ao mercado de trabalho submetendo a universidade a uma lógica de mercado sendo muitas vezes vista como uma empresa. Desta forma, todo conhecimento produzido na universidade é sempre submetido a uma comparação amparada na lógica comercial em que o conhecimento produzido é equiparado a um produto. Além disso, os índices acadêmicos estão sempre ligados à produtividade e ao volume do conhecimento produzido, índices que sempre estiveram ligados aos métodos de gestão comercial. Autores como Bernardo (2014) definiram este processo como "capitalismo acadêmico". Sendo assim, o poder de resistência da universidade pública em comparação ao poder quase nulo da universidade privada, já submetida ao mercado, é fundamental para suportar as forças impostas pelo capital financeiro através da globalização, inclusive nas realidades de pesquisa no campo do ensino de Geografia, como espaço de resistência a esse processo.

É fundamental ressalvar que a importância da universidade pública não se restringe unicamente a uma total resistência ao mercado, uma vez que as universidades públicas já estão inseridas em um sistema capitalista por si mesmas. Deve-se, portanto, confrontar os interesses do capital aos interesses da sociedade brasileira e alinhar os saberes acadêmicos aos interesses da nação, que nem sempre são perceptíveis a todos. Nesse sentido, é preciso garantir e aprofundar o debate sobre a fundamental necessidade de sobrevivência da universidade pública. Também é fundamental lutar por um maior acesso ao conhecimento e às universidades uma vez que nos países rigorosamente submetidos à lógica econômica da globalização, há uma "ênfase maior no valor econômico do conhecimento, tornando a luta pelo poder cada vez mais associada à luta pela distribuição do conhecimento e a possibilidade de acesso a ele" (KAWASAKI, 1997, p. 246). Sendo assim, as políticas de acesso à universidade pública são vitais para a sobrevivência da mesma, uma vez que dar acesso àquelas populações sempre excluídas dos processos e saberes acadêmicos é quebrar a visão de que a universidade está distante dos interesses nacionais além de destruir a bolha que se cria muitas vezes ao redor da universidade, ao trazer a população para dentro da esfera científica. 
Os trabalhos selecionados e apresentados no gráfico 5 possibilitam o entendimento da distribuição dos mesmos nas regiões do país definidas pelo IBGE.

Gráfico 5 - Número de trabalhos por região



Fonte: banco de dados da pesquisa (2020).

Nota-se que a maioria dos trabalhos foi realizada nas regiões sudeste e sul do país, as quais concentram $66 \%(n=81)$ dos trabalhos. É preciso salientar que a extração dessas informações foi realizada a partir da região de origem da universidade na qual estava inserido o Programa de Pós-Graduação, não levando em conta a UF de origem do pesquisador ou do local de onde foi realizada a pesquisa, como, por exemplo, a rede de ensino ou a instituição adotada para a investigação.

Dois pontos que merecem ser salientados é o fato de que apesar de a região centrooeste ter um número superior de trabalhos selecionados em relação a Região Nordeste, a primeira possui uma grande concentração em apenas uma universidade (de três universidades no total), enquanto no Nordeste as investigações são mais distribuídas entre as universidades (cinco no total). Outro ponto relevante é o fato de que a Região Norte possui apenas dois trabalhos sobre o tema e que estão todos na mesma universidade, a Universidade Federal do Amazonas (UFAM), pelo que pode ser observado no mapa 1.

Mapa 1 - Número de trabalhos por região 


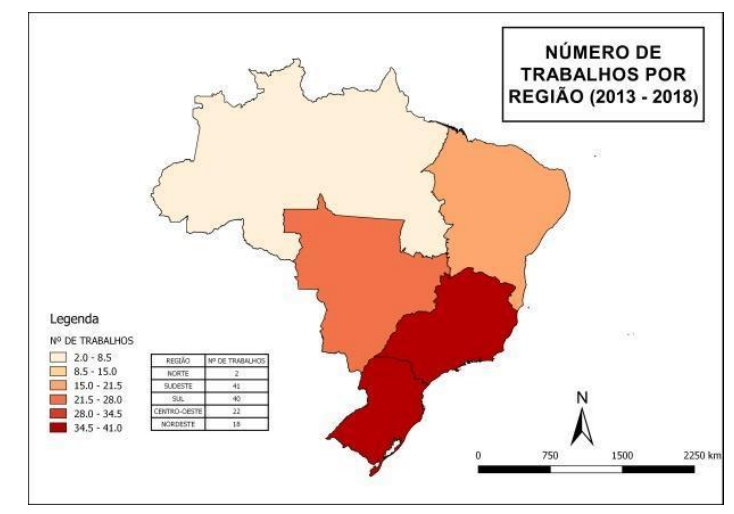

Fonte: banco de dados da pesquisa (2020).

As informações observadas no mapa acompanham aquelas relacionadas ao desenvolvimento econômico do país em que mostram as regiões Sul e Sudeste como mais desenvolvidas. Aqui cabe retomar a discussão já apresentada sobre o conceito de Região Concentrada, proposto e discutido por Santos (1986).

No gráfico 6, é possível observar a distribuição dos trabalhos selecionados para análise, entre trabalhos com bolsa e trabalhos sem bolsa no período de 2013 a 2018.

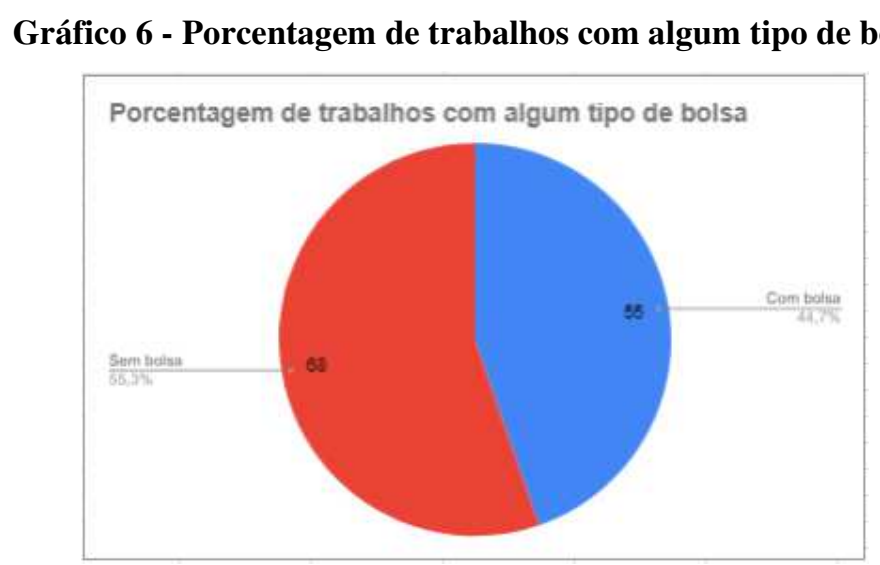

Fonte: banco de dados da pesquisa (2020).

A distribuição dos trabalhos no gráfico evidencia que 55,3\% (n=68) dos trabalhos não tiveram bolsa ou algum tipo de financiamento público, ou seja, a maioria das pesquisas que compuseram o corpus da presente investigação foram realizadas sem o amparo financeiro aos pesquisadores. Ainda, denota-se no gráfico 7, que no ano de 2013 a proporção de bolsas concedidas era de 1 para 1, ou seja, havia nove trabalhos com bolsa e nove sem bolsa. A partir daí, percebeu-se o início da diferença entre essas duas categorias e que se acentua a partir de 2015, justamente no momento em que o Brasil aprofunda a crise político-econômica e que 
estaria há poucos dias de ver a Emenda Constitucional n. ${ }^{\circ} 95$ diminuir as esperanças de uma maior distribuição de bolsas e verbas para a ciência.

\section{Gráfico 7 - Concessão de bolsas por ano}

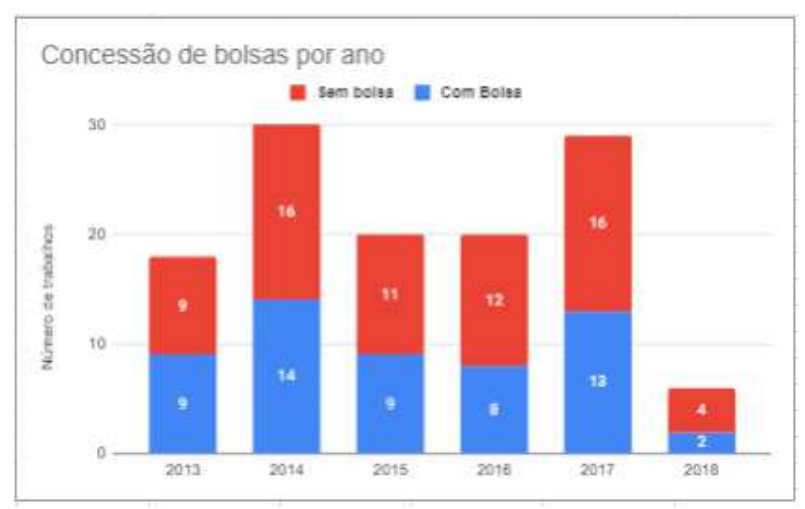

Fonte: banco de dados da pesquisa (2020).

As bolsas de pós-graduação são extremamente importantes para a formação de profissionais qualificados, uma vez que permitem ao pesquisador dedicar muito mais tempo ao seu trabalho e possuir condições de realização de sua investigação com maior dignidade. Essa importância fica ainda mais evidente quando se trata daquelas pós-graduações relacionadas às licenciaturas e ao campo da formação de professores. Somado ao fato, verifica-se que a remuneração dos professores ser mais baixa em relação às outras ocupações no país (MATIJASCIC, 2017), faz com que os profissionais docentes vislumbrem a pósgraduação também como forma de elevar seus rendimentos. Do mesmo modo, por ser uma profissão que demanda grande quantidade de horas, em função do planejamento das aulas, execução das mesmas e avaliação dos alunos e das atividades desenvolvidas por eles, conciliar a pós-graduação com a atividade profissional educativa trata-se de grande desafio para os professores. Por consequência, muitos professores se licenciam de suas atividades para se dedicar a complementação de sua formação e isso só é possível pela existência das bolsas no âmbito da pós-graduação, pois, do contrário, o profissional ficará dividido entre duas atividades extenuantes e que poderia comprometer outros aspectos da vida cotidiana.

As constatações feitas anteriormente dialogam com a Meta 16 do Plano Nacional de Educação (BRASIL, 2001) o qual define que até 2024, ao menos a metade dos professores da educação básica deverão ter como escolaridade mínima a pós-graduação. Sendo assim, a relevância das bolsas para os professores da educação básica é reforçada uma vez que a 
escolaridade de pós-graduado também consta como uma das estratégias para que se atinja essa meta. Segundo Mendonça et al (2017) cerca de 6\% dos professores da educação básica no Brasil não possuem educação secundária e $40 \%$ dos docentes do país têm escolaridade de ao menos 13 anos e, portanto, equivalente ou superior apenas à licenciatura curta. No mesmo estudo, observa-se que os profissionais que possuem formação superior e pós-graduação são maioria quando se observa a quantidade de profissionais com carteira assinada, ou seja, no âmbito da iniciativa privada.

Em resumo, o auxílio das bolsas na pós-graduação além de proporcionar maior empregabilidade aos docentes, também possibilita que a educação brasileira atinja maiores índices de qualidade ao formar profissionais mais qualificados. A atuação do governo federal perante as principais agências de fomento como Capes e CNPq, diminuindo as verbas para bolsas, gerará impacto diretamente negativo nessas leituras, precarizando ainda mais a profissão docente, que já é tão sucateada no país. Constata-se que o contrário já foi observado por Silva e Dantas (2017) quando afirmam que já houve no Brasil um aumento da procura pela pós-graduação atrelada a política de concessão de bolsas mais intensiva.

Observa-se, no gráfico 8, as agências financiadoras das bolsas dos trabalhos selecionados no trabalho, que tiveram esse aporte financeiro.

\section{Gráfico 8 - Agências financiadoras das bolsas}

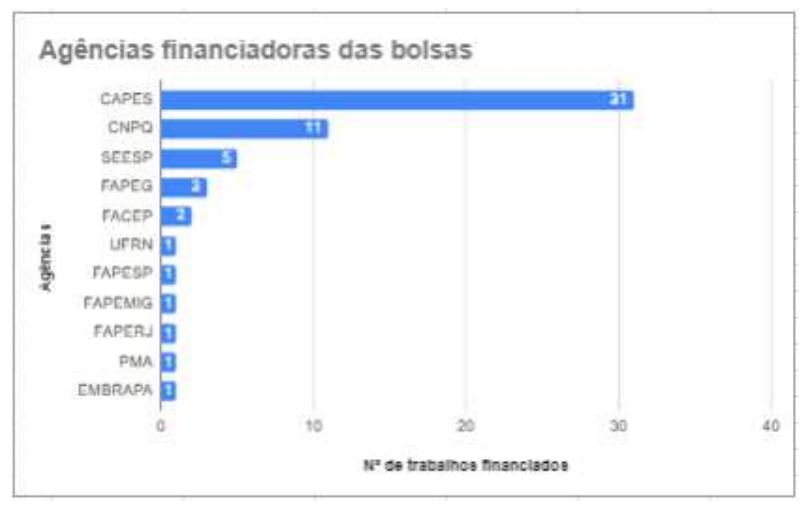

Fonte: banco de dados da pesquisa (2020).

Em uma leitura inicial, duas agências são as responsáveis por $76 \%(\mathrm{n}=42)$ dos trabalhos selecionados, de um total de 55 que tiveram bolsa. São elas: a Coordenação de Aperfeiçoamento de Pessoal de Nível Superior (Capes) e o Conselho Nacional de Desenvolvimento Científico e Tecnológico (CNPq). Esses dados acompanham o panorama nacional de fomento a pesquisa uma vez que são essas duas agências as maiores concedentes 
de bolsas para a pesquisa brasileira (JARDIM, 2020). Em 2014, os recursos para bolsas do Capes atingiram um pico de dois bilhões e quinhentos mil reais (JARDIM, 2020) e, a partir de 2015, os recursos passaram a cair gradativamente. No atual governo, os investimentos em ciência mal conseguem dar conta das bolsas já em andamento, sendo observados constantes cortes e diminuições do número das mesmas nas múltiplas realidades do país. As dissertações e teses são trabalhos que exigem grande dedicação e tempo, deste modo muitas vezes torna-se difícil ao pesquisador conciliar trabalho e vida acadêmica sem algum tipo de auxílio/bolsa. Em razão disso, a redução de recursos para bolsas do Capes e CNPq poderá refletir de maneira a diminuir a produção de pesquisas sobre práticas de ensino de Geografia no Brasil, dados os argumentos e reflexões propostas até o presente ponto das análises.

Destaca-se, também, a atuação das Fundações de Amparo à Pesquisa (FAPs), entidades estaduais que são instituições alternativas ao $\mathrm{CNPq}$ e Capes e que dão amparo financeiro aos trabalhos. Se utilizadas concomitantemente e dinamicamente com as agências de fomentos federais, os investimentos na pós-graduação e no financiamento de bolsas de pesquisa serão mais eficientes, pois, segundo Borges (2011), as FAPs possuem uma maior capilaridade nacional e, ainda, possuem o conhecimento das especificidades regionais e estaduais, entendida como a capacidade de dispersão da atuação das instituições no território. Aliado ao conhecimento regional e estadual, as FAPs se dão como boa estratégia de desenvolvimento das pesquisas. Apesar disso, não verifica-se, no campo das pesquisas em práticas de ensino em Geografia, uma maior presença das FAPs.

O poder de capilaridade das FAPs pode ser exemplificado a partir dos dados contidos na Tabela 1, tomando como exemplo a realidade da Fundação de Amparo à Pesquisa do Rio Grande do Sul (FAPERGS) no ano de 2017. 
Tabela 1 - Porcentagem dos recursos da FAPERGS destinadas às universidades

\begin{tabular}{|c|c|c|c|}
\hline UNIVERSIDADE & RECURSOS ALOCADOS & UNIVERSIDADE & RECURSOS ALOCADOS \\
\hline UFRGS & $23 \%$ & UCS & $3 \%$ \\
UFPEL & $12 \%$ & UPF & $3 \%$ \\
UFSM & $10 \%$ & FEEVALE & $2 \%$ \\
OUTRAS & $10 \%$ & HCPA & $2 \%$ \\
UNISINOS & $6 \%$ & ULBRA & $2 \%$ \\
PUCRS & $5 \%$ & UNIJUÍ & $2 \%$ \\
FURG & $5 \%$ & UNIVATES & $2 \%$ \\
UFCSPA & $5 \%$ & UNISC & $2 \%$ \\
UNIPAMPA & $4 \%$ & UFFS & $1 \%$ \\
\hline
\end{tabular}

Elaboração: os autores (2020). Fonte dos dados: FAPERGS (2017).

Observa-se que a FAPERGS atende a diversas universidades localizadas no interior do estado. Desta forma, um maior apoio das FAPs poderia desconcentrar os investimentos das agências de fomento dos principais centros de pesquisas nacionais e, além disso, dar apoio às pesquisas em práticas de ensino em Geografia que estudem as realidades do interior dos estados do Brasil, uma vez que já se constatou, através do gráfico 4, a concentração das pesquisas dentro do tema abordado neste trabalho nas principais universidades e centros de pesquisa do país. Segundo Matijascic (2017), a quantidade de professores com pós-graduação e domicílio em regiões urbanas não metropolizadas é quase duas vezes menor que o número de professores com pós-graduação e em domicílio metropolitano. Sendo assim, através das FAPs, seria possível obter maior qualificação dos docentes no interior dos estados através do fomento à pesquisa, dando auxílio aos pós-graduandos com bolsas e assim possibilitando e incentivando uma maior titulação de mestres e doutores nessas regiões do país que pouco recebem recursos das agências predominantes.

É possível verificar, no gráfico 9, a distribuição dos trabalhos conforme o conceito do Programa de Pós-Graduação em que foi realizada a pesquisa, de acordo com a avaliação Capes do ano de 2017. 
Gráfico 9 - Conceitos dos PPGs de origem

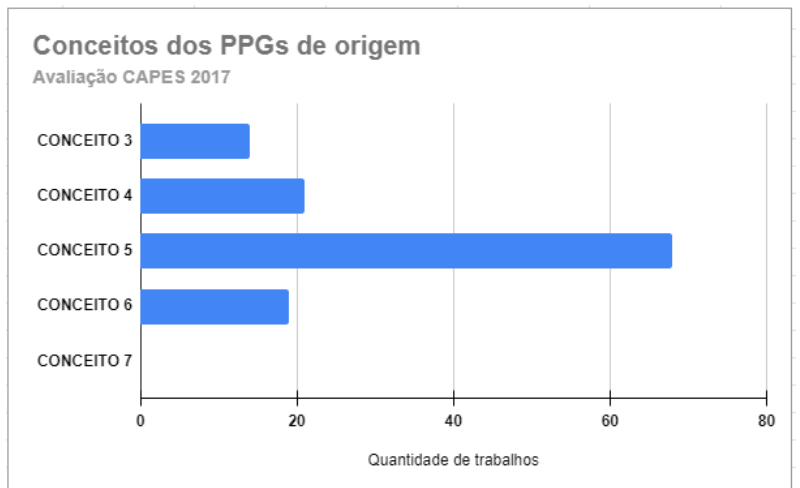

Fonte: banco de dados da pesquisa (2020).

Com base na classificação da Capes, considera-se programas de conceito 3 , 4 e 5 como "bons" e os programas com conceito 6 e 7 como "programas de excelência". Nota-se que a ampla maioria dos trabalhos são provenientes de PPGs com conceito 5, considerados programas “bons". Os conceitos dos PPGs foram extraídos da última Avaliação Quadrienal da Capes e apenas 19 trabalhos foram realizados em programas considerados de "excelência", com conceito 6. O que se observa através do gráfico é uma expressiva diferença entre aqueles trabalhos desenvolvidos em PPGs com conceito 5 daqueles desenvolvidos em PPGs de conceito 6. Também há uma grande diferença para os conceitos inferiores a 5. Nenhum trabalho pertenceu a um programa de pós-graduação conceito 7.

Nesse sentido, há, pelo menos, duas considerações a serem empregadas. A primeira, diz respeito ao fato de que a maioria dos trabalhos $(n=68$ ou $54 \%$ do total) está concentrada no conceito que mais se aproxima dos dois mais elevados (conceitos 6 e 7). A segunda, leva à interpretação de que é clara a necessidade de que se desenvolvam mais trabalhos a respeito do tema em programas de excelência.

É preciso levar em conta quando se comenta a temática de conceitos da avaliação da Capes a particularidade do tempo (SILVA; DANTAS, 2017), pois há um histórico diverso da formação dos PPGs no território brasileiro. É fato que cursos recém criados ou com pouco tempo de existência são mais suscetíveis a ter conceitos menores em relação àqueles mais antigos, pela própria normatização da Capes. Sendo assim, regiões que tiveram cursos de pósgraduação criados apenas recentemente, terão PPGs com conceitos baixos e esse é apenas um dos fatores que tornam essa temática de avaliação dos PPGs pela Capes um debate polêmico. 
Os critérios utilizados pela Capes na avaliação dos PPGs são: proposta do programa; corpo docente; corpo discente, teses e dissertações; produção intelectual e inserção social. As discussões em torno dos critérios giram em torno do estímulo ou não a um viés produtivista da pós-graduação. A necessidade de se atender da melhor forma aos critérios estipulados pela Capes para angariar mais verbas para os programas leva a uma corrida pelo maior número de produções. Porém, os critérios também levam em conta a distribuição dessa produção entre os integrantes do corpo docente, a qualidade das produções, a qualidade dos meios em que os trabalhos são publicados e sua inserção social. Sendo assim, de certa forma há um equilíbrio de importância entre os critérios analisados. No entanto, segundo Kawasaki (2017, p. 108), as orientações dadas pelas Comissões de Avaliação é de "atribuir aos quesitos 3 e 4 os maiores pesos" enquanto o peso do quesito 1 é quase nulo. Dessa forma, o produtivismo apontado nas discussões a respeito do tema se manifesta. Os critérios de avaliação criam muitas vezes um círculo vicioso apontado por Horta e Moraes (2005) em que programas com conceitos elevados focam na produtividade, garantindo seus conceitos e angariando mais verbas, porém formando menos alunos. Enquanto isso, programas com conceitos mais baixos se preocupam em formar mais alunos e publicar menos.

No entanto, este tipo de avaliação poderá aumentar as desigualdades entre os programas por não levar em consideração o tempo que os mesmos foram criados. Um programa recém criado levará mais tempo para elevar seus índices de produtividade e, logicamente, terá mais dificuldade em atrair pesquisadores mais conceituados e com extensa produção acadêmica. Isso faz com que esses programas tenham um mau desempenho na avaliação e tenham direito a menos verbas. Tais realidades, quando apontadas à pesquisa no campo das práticas de ensino de Geografia poderia parecer desconexa, entretanto, as conexões entre a formação docente e a pós-graduação brasileira vêm se aprofundando cada vez mais.

\section{CONSIDERAÇÕES FINAIS}

O aumento no número de pesquisas relacionadas às práticas de ensino em Geografia tem sido um ponto positivo no âmbito da Geografia brasileira. Nessa perspectiva, é de absoluta importância conhecer o que está sendo produzido, como estão sendo produzidas as investigações e quais são as tendências temáticas, bem como diversas outras análises possíveis mediante as informações apresentadas nos trabalhos. Desse modo, a presente 
pesquisa registrou o intuito de pensar a respeito do que se produz, em nível de pós-graduação, sobre as práticas de ensino de Geografia.

Este trabalho foi construído através do estado do conhecimento que proporcionou realizar o levantamento, registro, categorização que deram condições para que se realizasse a análise e síntese do material selecionado. Da mesma forma, o estado do conhecimento forneceu as condições necessárias para se averiguar o estado que se encontra a ciência, suas peculiaridades e poder contribuir para o ineditismo das produções. Foram selecionados trabalhos entre os anos de 2013 e 2018 que estavam catalogados no Instituto Brasileiro de Informação em Ciência e Tecnologia através do banco de dados disponível na Biblioteca Digital Brasileira de Teses e Dissertações (BDTD). A seleção foi feita através das palavras chaves e leitura dos resumos dos trabalhos. Após, prosseguiu-se com extração de dados e posterior análise e síntese.

Observou-se que 85,4\% $(n=105)$ dos trabalhos eram dissertações e que a distribuição dos trabalhos entre os anos de 2013 e 2018 não se dá de forma uniforme havendo significativas diferenças entre os anos. Em relação às universidades, destacam-se aquelas da região sul e sudeste. A UFRGS foi a universidade que mais teve trabalhos produzidos relacionados ao tema, seguido da Universidade Federal de Goiás que se destaca por ser a única a não fazer parte da região Sul e Sudeste entre as cinco universidades que mais produziram e por concentrar a maior parte das produções do Centro-Oeste. Ademais, verificou-se que 55,3\% ( $\mathrm{n}=68)$ dos trabalhos não tiveram nenhum tipo de bolsa e que a quantidade de trabalhos sem bolsa foi aumentando ao longo do período em relação ao número de trabalhos com bolsa. Ao mesmo tempo, observou-se que o Capes e CNPq continuam sendo a maior fonte de financiamento das bolsas e que as Fundações de Amparo à Pesquisa foram pouco presentes. Por último, foi averiguado que a maior parte dos trabalhos são desenvolvidos em PPGs de conceito 5, considerados "bons".

Foi possível neste trabalho analisar e sintetizar informações sobre os aspectos quantitativos das pesquisas em práticas de ensino em Geografia que não haviam sido reunidas anteriormente. Espera-se com isso contribuir para os atuais e futuros pesquisadores a conhecer as especificidades do tema e, nesse sentido, encontrar no presente texto possibilidades e leituras para o desenvolvimento de suas investigações. 
Há muita discussão em torno da relação entre qualidade e produtividade estabelecida através dos critérios da Capes tanto para qualificação do Programa de Pós-Graduação quanto para a consequente distribuição de bolsas e verbas. Isso se deve, entre outros motivos, a um processo de quantificação de um fenômeno qualitativo. Sendo assim, tem se observado há algum tempo a contaminação dos conceitos capitalistas em praticamente todas as esferas da vida. Com a pós-graduação não foi diferente. Ao longo da formação da pós-graduação do Brasil tem se assimilado o conceito de produtividade tanto como fim quanto meio para o desenvolvimento da ciência no Brasil. Neste contexto, critérios de avaliação e de distribuição de bolsas que levam em consideração, entre outras coisas, a quantidade de alunos formados e a quantidade de publicações levam a uma produção exacerbada de artigos e trabalhos. Luiz (2006, p. 302) credita a isso o crescimento de algo que pode ser considerado "lixo acadêmico", ou seja, "textos que jamais foram ou serão utilizados por outrem, talvez sequer para leitura, mesmo quando publicados em periódicos ditos de respeitabilidade internacional".

Saviani (2010) reforça essa ideia ao lembrar que o termo produtividade provém da concepção capitalista de se produzir mais em menos tempo e que está relacionado em sua gênese com a produção material. Neste contexto específico, pode-se observar o crescimento da produtividade e qualidade, simultaneamente, uma vez que é possível separar o produto de seu ato de produção. Este fato não se observa inteiramente na produção científica uma vez que ela não é material. Portanto, não é factível haver aumento de produtividade e qualidade concomitantemente na produção científica. Deste modo, ambos autores, embora por justificativas distintas e não excludentes entre si, concordam que a exigência de aumento de produtividade entra em rota de colisão com a exigência de qualidade da produção acadêmica. A solução, não tão próxima de nossa realidade, seria o rompimento da produção acadêmica com a lógica do capital (SAVIANI, 2010). Sendo assim, é urgente que se instale um sistema de avaliação menos pior e que foque mais na qualidade do que na produtividade. Para isso, é necessário que, inicialmente, se explicitem as fragilidades e contradições do sistema vigente.

As pesquisas em práticas de ensino em Geografia estão em plena ascensão quando se fala em quantidade de trabalhos. Nessa perspectiva, é mandatório que se pense a respeito dos rumos que as pesquisas estão tomando. Os dados apresentados no trabalho dão conta dos aspectos quantitativos das pesquisas embora as análises não tenham se restringido apenas a esse aspecto. As investigações que buscam pensar, refletir e promover debate sobre o ensino 
de Geografia têm nos ensinado que a resistência segue sendo palavra de ordem quando se fala em pesquisa para a formação e qualificação de professores no Brasil. Duplas, triplas ou quádruplas jornadas de trabalho, enfrentamento de condições de pesquisa sem fomento, disputas por conceitos de PPGs são apenas alguns elementos que são colocados na realidade dos pesquisadores sobre práticas de ensino de Geografia no país. Resta, por fim, associar-nos ao colocado por Schopenhauer (1851): “A tarefa não é tanto ver aquilo que ninguém viu, mas pensar o que ninguém ainda pensou sobre aquilo que todo mundo vê." Fica, portanto, o convite para que sigamos pensando mais sobre aquilo que está à nossa frente, no campo do ensino de Geografia.

\section{AGRADECIMENTOS}

À Pró-Reitoria de Pesquisa da Universidade Federal do Rio Grande do Sul pela concessão da bolsa de iniciação científica BIC/UFRGS.

\section{REFERÊNCIAS}

AALBERS, M. The potential for financialization. Dialogues in Human Geography, v. 5, n. 2, 2015. Disponível em: https://journals.sagepub.com/doi/10.1177/2043820615588158 Acesso em: 11 nov. 2020.

BERNARDO, M. H. Produtivismo e precariedade subjetiva na universidade pública: o desgaste mental dos docentes. Psicologia e Sociedade, Belo Horizonte, v. 26, n. spe, 2014. Disponível em: http://www.scielo.br/scielo.php?script=sci_arttext\&pid=S010271822014000500014\&lng=en\&nrm=iso. Acesso em: 11 nov. 2020.

BORGES, Mario Neto. As fundações estaduais de amparo à pesquisa e o desenvolvimento da ciência, tecnologia e inovação no Brasil. Revista USP, n.89, 2011. Disponível em: https://www.revistas.usp.br/revusp/article/view/13876/15694 Acesso em: 15 nov. 2020.

BRASIL. Lei n. 10.172, de 9 de Janeiro de 2001. Aprova o Plano Nacional de Educação (2001-2010) - PNE e dá outras providências. Diário Oficial da União, Brasília, DF, 10 jan. 2001. Disponível em: http://www.planalto.gov.br/ccivil_03/leis/leis_2001/110172.htm Acesso em: 15 nov. 2020.

BRASIL. Ministério da Saúde. Conselho Nacional de Saúde. Resolução no 510, de 7 de abril de 2016. Diário Oficial da República Federativa do Brasil, Brasília, DF, 24 maio 2016 a. Disponível em: https://bvsms.saude.gov.br/bvs/saudelegis/cns/2016/res0510_07_04_2016.html Acesso em: 13 nov. 2020. 
BRASIL. Emenda Constitucional 95. Altera o Ato das Disposições Constitucionais Transitórias, para instituir o Novo Regime Fiscal, e dá outras providências. Diário Oficial da União, Brasília, 16 dez. 2016b. Disponível em:

https://www2.camara.leg.br/legin/fed/emecon/2016/emendaconstitucional-95-15-dezembro2016-784029-publicacaooriginal-151558-pl.html Acesso em: 10 nov. 2020.

CORREAA, W. da S. O estado da arte do ensino de geografia no Brasil a partir do uso de novas tecnologias. 2019. 140 f. Dissertação (Mestrado em Geografia) - Universidade Federal do Amazonas, Manaus, 2019.

ELIAS, D. Milton Santos: a construção da geografia cidadã. Geosul, Florianópolis, v.18, n.35, 2003. Disponível em: https://periodicos.ufsc.br/index.php/geosul/article/view/13606 Acesso em: 25 nov. 2020.

FERREIRA, N. S. de A. As pesquisas denominadas "estado da arte". Educação e Sociedade, Campinas, v. 23, n. 79, 2002. Disponível em:

http://www.scielo.br/scielo.php?script=sci_arttext\&pid=S0101-

73302002000300013\&lng=en\&nrm=iso Acesso em: 25 nov. 2020.

FISCHER, T. Mestrado profissional como prática acadêmica. Revista Brasileira de PósGraduação, v. 2, n. 4, 2005. Disponível em:

http://ojs.rbpg.capes.gov.br/index.php/rbpg/article/view/74 Acesso em: 25 nov. 2020.

FONSECA, R. L. O Estado da Arte das Pesquisas em Ensino de Geografia publicadas em Periódicos Nacionais: perspectivas e tendências. Caderno de Geografia, v.29, n.59, Belo Horizonte, 2019. Disponível em:

http://periodicos.pucminas.br/index.php/Geografia/article/view/20922 Acesso em: 25 nov. 2020 .

FONSECA, R. L. et al. O estado da arte das pesquisas em dissertações de mestrado em ensino de Geografia: contribuição para uma avaliação a partir das pesquisas nos programas nacionais de stricto sensu (2008 - 2012). Revista da ANPEGE, v. 10, n. 13, 2017. Disponível em: https://ojs.ufgd.edu.br/index.php/anpege/article/view/6480 Acesso em: 26 nov. 2020.

GIL, A. C. Como elaborar projetos de pesquisa. 4. ed. São Paulo: Atlas, 2007.

GUIMARÃES, I. V. Ensinar e aprender Geografia na Base Nacional Comum Curricular. Ensino Em Re-Vista, Uberlândia, MG, v.25 , n.Especial, p. 1036-1055, 2018. Disponível em: http://www.seer.ufu.br/index.php/emrevista/article/view/46456/24953 Acesso em: 28 abril 2021.

HORTA, J. S. B.; MORAES, M. C. M. de. O sistema Capes de avaliação da pós-graduação: da área de educação à grande área de ciências humanas. Revista Brasileira de Educação, n. 30, 2005. Disponível em: https://www.scielo.br/scielo.php?script=sci_arttext\&pid=S141324782005000300008 Acesso em: 26 nov. 2020. 
JARDIM, C. E. A Expansão e o Financiamento da Pós-Graduação no Brasil e a Meta 14 do Plano Nacional de Educação. FINEDUCA - Revista de Financiamento da Educação, v. 10, 2020. ISSN 2236-5907. Disponível em: https://seer.ufrgs.br/fineduca/article/view/87919 Acesso em: 13 out. 2020.

KAWASAKI, Cl. S. Universidades públicas e sociedade: uma parceria necessária. Revista da Faculdade de Educação, São Paulo, v. 23, n. 1, 1997. Disponível em: http://www.scielo.br/scielo.php?script= sci_arttext \& pid=S0102-25551997000100013 \& lng=en\nrm=iso Acesso em: 11 nov. 2020.

KAWASAKI, B. C. Critérios da avaliação da capes para programas de pós graduação. Revista Adusp, v. 1, maio, 2017. Disponível em: https://www.adusp.org.br/files/revistas/60/mat10.pdf Acesso em: 11 nov. 2020.

LENCIONI, S. Linhas de pesquisa da pós-graduação em geografia. mudanças, esquecimentos e emergência de (novos) temas. Revista da ANPEGE, [S.1.], v. 9, n. 11, p. 5-19, jul. 2017. ISSN 1679-768X. Disponível em: https://ojs.ufgd.edu.br/index.php/anpege/article/view/6487. Acesso em: 24 abr. 2021.

LUIZ, R. R. Avaliação de produtividade acadêmica: uma proposta de quantificação. Revista Brasileira de Pós-Graduação, v. 3, n. 6, 11. Disponível em: https://rbpg.capes.gov.br/index.php/rbpg/article/view/112 Acesso em: 27 abril 2021.

MATIJASCIC, M.. Professores da Educação Básica no Brasil: condições de vida, inserção no mercado de trabalho e remuneração. Rio de Janeiro: Instituto de Pesquisa Econômica Aplicada; 2017. Disponível em:

https://www.ipea.gov.br/portal/index.php?option=com_content\&view=article\&id=30338 Acesso em: 11 nov. 2020.

MENDONÇA, F. et al. A geografia da saúde no Brasil: estado da arte e alguns desafios. Investigaciones Geográficas, n. 48, 2014. Disponível em: https://dialnet.unirioja.es/servlet/articulo?codigo=5793880 Acesso em: 11 nov. 2020.

MORAES, J. V. de; CASTELLAR, Sonia Maria Vanzella.Metodologias ativas para o ensino de Geografia: um estudo centrado em jogos. Revista Electrónica de Enseñanza de las Ciencias, v.17, n.2, p. 422-436, 2018. Disponível em: http://reec.uvigo.es/volumenes/volumen17/REEC_17_2_07_ex1324.pdf. Acesso em: 26 de abril de 2021.

MORAES, J. V.; CASTELlAR, S. M. V.; SACRAMENTO, A.C.R.. Jogos e resolução de problemas para o entendimento do espaço geográfico no ensino de Geografia.In: Helena Copetti Callai. (Org.). Educação Geográfica-Reflexão e Prática. 2ed.Ijuí: UNIJUÍ, 2014, v. 1, p. 249-276.

MORAN, J. Metodologias ativas para uma aprendizagem mais profunda. In: BACICH, L.; MORAN, J. Metodologias ativas para uma educação inovadora: uma abordagem teórico- 
prática. Porto Alegre: Penso, 2018. p. 1-25. Disponível em: http://www2.eca.usp.br/moran/wp-content/uploads/2013/12/metodologias_moran1.pdf. Acesso em: 27 de abril de 2021.

MOROSINI, M. C.; FERNANDES, C. M. B. Estado do Conhecimento: conceitos, finalidades e interlocuções. Educação Por Escrito, Porto Alegre, v. 5, 2014. Disponível em: https://revistaseletronicas.pucrs.br/ojs/index.php/porescrito/article/view/18875 Acesso em: 25 nov. 2020.

PAZIO, E; GOMES, M. de F. As geotecnologias no ensino de Geografia: o estado da arte da pesquisa e as contribuições para a formação de professores. In: EDUCERE, 2015, Curitiba. XII Congresso Nacional de Educação 2015. Disponível em: https://educere.bruc.com.br/arquivo/pdf2015/19882_8321.pdf Acesso em: 25 nov. 2020.

RABELO, K. S. de P; BORBA, O. de F. O estado da arte da pesquisa sobre metodologias ativas no ensino de Geografia: as contribuições para uma ressignificação do ensino. In: Anais do $14^{\circ}$ Encontro Nacional de Prática de Ensino de Geografia: políticas, linguagens e trajetórias, 2019. Disponível em:

https://ocs.ige.unicamp.br/ojs/anais14enpeg/article/view/3118 Acesso em: 25 nov. 2020.

SANTOS, M. A região concentrada e os circuitos produtivos. Texto apresentado como parte do relatório de pesquisa do projeto O Centro Nacional: Crise Mundial e Redefinição da Região Polarizada, 1986 (datilografado).

SAVIANI, D. O dilema produtividade-qualidade na pós-graduação. Nuances: estudos sobre Educação. Presidente Prudente, v. 17, n. 18, p. 32-49, 2010. Disponível em:

https://revista.fct.unesp.br/index.php/Nuances/article/view/723 Acesso em: 27 abril 2021.

SCHOPENHAUER, A. Sobre a filosofia e seu método. 1851 (datilografado).

SILVA, J. B. da; DANTAS, E. W. C. A pós-graduação em geografia no Brasil: uma contribuição à política de avaliação. Revista da ANPEGE, v. 2, n. 02, 2017. Disponível em: https://ojs.ufgd.edu.br/index.php/anpege/article/view/6609 Acesso em: 13 nov. 2020.

SILVA, J. B. da. A pesquisa e a produção geográfica. Revista da ANPEGE, v. 7, n. 01, 2017. Disponível em: https://ojs.ufgd.edu.br/index.php/anpege/article/view/6559 Acesso em: 29 out. 2020.

SILVA, R. B. da. A relação universidade-sociedade na periferia do capitalismo. Revista Brasileira de Ciências Sociais, São Paulo, v. 27, n. 78, p. 25-40, Feb. 2012. Disponível em: http://www.scielo.br/scielo.php?script=sci_arttext\&pid=S010269092012000100002\&lng=en\&nrm=iso. Acesso em: 27 Abril 2021. 